\title{
Research on Safety Risk Assessment Method of Highway Bridge Construction Based on AHP-Fuzzy Comprehensive Evaluation
}

\author{
Zhuang Guofeng ${ }^{1}$ \\ ${ }^{1}$ Shanghai University, Department of Civil Engineering, Shanghai, 200444, China
}

\begin{abstract}
The quality of road and bridge engineering is directly related to the safety of the transportation industry. In the construction of highway bridges, it is particularly important to strictly control the construction quality. Combining the analytic hierarchy process and the fuzzy comprehensive evaluation method, the AHP-fuzzy comprehensive evaluation method is used to obtain the current road bridge construction safety risk level. According to the different risk levels, effective measures should be taken to avoid unsafe accidents. On this basis, historical risk cases can be analyzed to find problems in the safety assessment of highways and bridges, and effective construction safety management and control measures can be put forward to ensure the vigorous development of my country's highway and bridge industry.
\end{abstract}

\section{Introduction}

With the continuous increase in the number of vehicles, the burden on the original road has been increased, so the country has increased the construction of road bridges. Compared with other projects, the construction period of bridge is long, the cost is high, and the construction is difficult. The safety problems generated in each construction project have become more and more prominent, so the quality requirements of construction technology are stricter[1-3]. In order to improve the effectiveness of construction and ensure the safe passage of vehicles, it is particularly critical to do a good job in the safety assessment of the entire stage of construction. It is necessary to put forward effective construction safety management and control measures to provide reliable guarantee for the passage of vehicles[4-6].As one of the important elements of transportation, bridges have the characteristics of multiple hazards in engineering construction. At the same time, bridge engineering is also a type of construction engineering[7]. There are many major occupational disasters that occur every day, there are more uncertainties in the risks of bridges during the construction process. If the risk level is too high, it will cause a risk of harmful bodies or objects[8].Therefore, discussing the engineering safety risk control of road and bridge engineering is particularly significant. Although engineering safety risk control is only an indicator of the overall profitability of construction projects, relevant studies around the world have pointed out that, in addition to the active performance indicators such as progress, cost, and quality, construction management is concerned with engineering safety risks from the perspective of damage prevention[9-11]. Control also has the necessity of its discussion. There are as many as hundreds of thousands of highway bridges in my country, and their use varies depending on the way of using. The function of road bridges is to cross the two ends of specific traffic[12]. Risks in the construction of bridges require attention, and different risks may also be transformed to a certain extent, causing greater risks.

\section{AHP-Fuzzy Comprehensive Evaluation Method}

For risk evaluation, an indicator system can be established. When performing indicator analysis, it is generally hoped that the indicators can be quantified so that accurate analysis and evaluation can be made. However, for some indicators that cannot or are difficult to quantify, we need to use qualitative methods to carry out Evaluation. At the same time, the scientificity and reliability of the evaluation system are also very important. Evaluation indicators must be able to scientifically reflect the actual situation and help the actual implementation. when the relevant indicators are reliable can they play a role in the actual process. If the content of the evaluation is irrelevant, the evaluation has no value. To evaluate the level of safety risk scientifically and reliably, the actual situation must be considered, the evaluation indicators must be in line with reality, and the evaluation indicators of different construction content must be analyzed in a targeted manner to achieve more accurate results.

The main factors affecting the safety risk of highway and bridge construction are divided into three levels. First, the target layer is represented by A, which directly reflects the ability of risk; the second is the sub-target layer, which involves safety management, facility risk, and Several indicators such as the surrounding

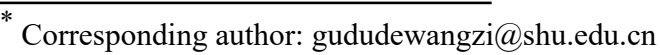


environment are represented by $\mathrm{B}_{1}, \mathrm{~B}_{2}$, and $\mathrm{B}_{3}$; the last is the basic indicator layer, these indicators are actually a refinement of the indicators of the previous layer, and the indicator of safety management can be specifically divided into personnel safety management and facility safety management, the corresponding indicator symbols are $C_{1}$ and $C_{2}$; the facility risk factor indicator can be further refined into several indicators such as bridge area, equipment service life, rescue equipment,equipment with historical risks and protective measures. The corresponding index symbols are $\mathrm{C}_{3}, \mathrm{C}_{4}, \mathrm{C}_{5}, \mathrm{C}_{6}, \mathrm{C}_{7}$. The indicator of the surrounding environmental factors can be refined into the degree of environmental complexity and the degree of environmental governance, which are respectively $\mathrm{C}_{8}$ and $\mathrm{C}_{9}$.

Let $\mathrm{C}$ be the set of factors and refer to the characteristics of the hierarchical structure. Here we need to determine the affiliation of the upper and lower factors. When making specific judgments, we need to use the expert investigation method.Through a large number of investigations and comparisons, we can judge the importance of different factors, As shown in Table 1.

Table 1. Comparison Table

\begin{tabular}{|c|c|c|}
\hline Scaling & Definition & Meaning \\
\hline 1 & $\begin{array}{c}\text { Equal } \\
\text { importance }\end{array}$ & $\begin{array}{c}\text { Two elements are } \\
\text { equally important to an } \\
\text { attribute }\end{array}$ \\
\hline 3 & $\begin{array}{c}\text { Slightly } \\
\text { important }\end{array}$ & $\begin{array}{c}\text { One element is slightly } \\
\text { more important than } \\
\text { the other }\end{array}$ \\
\hline 7 & $\begin{array}{c}\text { Obviously } \\
\text { important }\end{array}$ & $\begin{array}{c}\text { One element is } \\
\text { obviously more } \\
\text { important than another }\end{array}$ \\
\hline 9 & $\begin{array}{c}\text { Extrongly } \\
\text { important }\end{array}$ & $\begin{array}{c}\text { One element is more } \\
\text { important than another }\end{array}$ \\
\hline $2,4,6,8$ & Median & $\begin{array}{c}\text { One element is } \\
\text { extremely important } \\
\text { than the other }\end{array}$ \\
\hline $\begin{array}{c}\text { Reciproca } \\
1 \text { of scale }\end{array}$ & $\begin{array}{c}\text { Inverse } \\
\text { the trade-off between } \\
\text { two adjacent scales }\end{array}$ \\
\hline
\end{tabular}

If the criterion here is selected as the sub-target level factor $\mathrm{Bk}$, and various factors in the basic index level dominate it, then comparing the importance of $\mathrm{C}_{\mathrm{i}}$ and $\mathrm{C}_{\mathrm{j}}$, the corresponding proportional scale $\mathrm{C}_{\mathrm{ij}}$ can be obtained. Judge the relative importance between the two, and obtain the $\mathrm{n}^{*} \mathrm{n}$ order judgment matrix by comparison as $\mathrm{B}_{\mathrm{k}}=\left(\mathrm{C}_{\mathrm{ij}}\right)_{\mathrm{n}} \mathrm{n}_{\mathrm{n}}$.

\subsection{Calculate the relative weight of elements under a single criterion}

At present, there are many methods that can be used in the calculation of the sorting weight vector, among which the least square method(LS), the characteristic root method $(\mathrm{CR})$ and the upper triangle element method
(UTE) are more typical. If the accuracy requirements are not strict, it is ideal to use the characteristic root method, which has been widely used in practical engineering. In view of this, this method was chosen in the study. Here is a brief introduction to its calculation process. First, calculate its $R_{\max }$ for the specific judgment matrix $A$, which is the value of the maximum eigenvalue, and then you can get the eigenvector $W$. Since $A W=R_{\max } W$, the relative weight of each factor The size of can be represented by the feature vector $\mathrm{W}$.

\subsection{Fuzzy comprehensive evaluation}

On the basis of making full use of subjective information, the fuzzy comprehensive evaluation method has achieved good application effects in risk evaluation. It is worth mentioning that this method is more ideal when there is an expert jury. Therefore, this method is used in the research. Through the effective combination of tomographic analysis and fuzzy comprehensive evaluation method, this paper makes a reasonable evaluation of various indicators that affect the safety risk of highway bridges, and aims at establishing a good indicator system. Fuzzy comprehensive evaluation is carried out from level one to level two.

\subsubsection{Establish related fuzzy sets}

Step1: Establish a collection of evaluation indicators $\mathrm{C}=\left\{\mathrm{C}_{1}, \mathrm{C}_{2}, \ldots \ldots, \mathrm{C}_{9}\right\}$, This set represents the basic level of evaluation indicators.

Step2: Establish a set of comment levels, use an expert review panel to evaluate all indicators, and give the evaluation terms of each indicator at the same time. The evaluation terms here are divided into excellent, good, medium, weak, and poor grades, and the safety of each indicator The situation is evaluated. Among them, the set of evaluation data is represented by $V=\left\{V_{1}, V_{2}\right.$, $\left.\mathrm{V}_{3}, \mathrm{~V}_{4}, \mathrm{~V}_{5}\right\}$. In order to quantify it, the comment set is converted into a quantized set $\mathrm{V}=\{5,4,3,2,1\}$, the numbers in it represent excellent, good, medium, weak and poor grades respectively.

\subsubsection{Determine the judgement matrix}

The expert evaluation team in this article has a total of 100 members ( 100 members belong to the preliminary drafting stage, the number of members can be adjusted according to the actual situation) combined with the basic status quo of certain city to evaluate various indicators and give corresponding scores. For indicator set $\mathrm{C}$, the membership vector of any indicator $\mathrm{C}_{\mathrm{i}}$ to comment set $\mathrm{v}$ is $\mathrm{Rci}=\left(\mathrm{r}_{\mathrm{ci} 1}, \mathrm{r}_{\mathrm{ci} 2}, \mathrm{r}_{\mathrm{ci} 3}, \mathrm{r}_{\mathrm{ci} 4}, \mathrm{r}_{\mathrm{ci} 5}\right), \mathrm{i}=1,2$, $3,4,5, \ldots .$. . The $r_{\text {cim }}$ can be obtained through the scoring opinions of each member of the statistical expert group, which means that $\mathrm{C}_{\mathrm{i}}$ has $\mathrm{V}_{\mathrm{i} 1} \mathrm{~V}_{1}$ reviews, and so on in other cases. Through the above method, the index membership vector can be determined, and then the judgment matrix about the index membership vector can be obtained. In the study, the evaluation opinions of 100 
experts were collected, and the scores of various indicators of bridge safety risk were summarized. Based on this, the corresponding weight values were set reasonably, and finally the judgment matrix $R_{k}$ of each level was obtained as follows:

$$
R_{\mathrm{k}}=\left[\begin{array}{l}
r_{11} \ldots \ldots r_{1 j} \ldots \ldots r_{15} \\
\ldots \ldots \ldots \ldots \ldots \ldots \ldots . . . \\
r_{i 1} \ldots \ldots r_{i j} \ldots \ldots r_{i 5}
\end{array}\right]
$$

Among them, the judgment matrix of the first level of quality assurance is represented by $R_{k}(k=0,1,2,3)$, which is the second level index, and the score for each factor is $r_{i j}(j=1,2,3,4,5)$ to represent, and then can obtain the weight of different scores.

\subsubsection{Fuzzy comprehensive evaluation}

As mentioned above, the use of fuzzy comprehensive evaluation method to evaluate various indicators needs to be based on a weighted average model, which can comprehensively consider various factors, while also covering all the information of the judgment matrix. The entire modeling process needs to use the principle of matrix multiplication.

$$
B=\mathrm{W}_{\mathrm{i}} * R_{\mathrm{i}}
$$

Among them, the judgment matrix is represented by $\mathrm{B}$, and the weight vector is represented by $\mathrm{R}$, which is the membership vector of the comment set $\mathrm{V}$.

\section{Control measures}

After using the model to understand the degree of risk,in the construction of roads and bridges, mechanical equipment is something that must be used. Improper use of mechanical equipment will also cause a series of unsafe accidents. The quality of highway bridge construction is determined by many factors, among which the quality of the construction personnel is the first factor, because each link of the highway bridge construction project is determined by people. If the highway construction unit lacks relevant professional talents, and the knowledge of the relevant practitioners is insufficient, or even the individual's physical condition is poor, and there is no relevant project engineering experience, it will affect the construction of highway and bridge engineering. The construction of highway and bridge projects is difficult. For example, some highway and bridge projects need to cross canals, which are unpredictable and dangerous to a certain extent. Based on this, the construction engineering of highway bridges requires a lot of technology and talents, and the requirements are very highly. Only when relevant construction personnel possess professional knowledge and good practical operation ability can the construction quality of highway and bridge construction projects be guaranteed to a certain extent. For construction operators, the construction technology level of relevant personnel is not sufficient to meet the relevant requirements of highway construction projects, which will have a negative impact on highway bridge construction and lead to unqualified highway construction quality. In terms of management personnel related to bridge construction, the relevant professional capabilities of construction personnel have limitations. The relevant supervisors do not have the ability to conduct inspections, nor can they provide useful opinions and suggestions. The construction will lead to the blind or wrong guidance of the management personnel, which will have a fundamental impact on the overall construction quality of the bridge project.Due to the huge amount of highway and bridge engineering, more or less unexpected situations will be encountered during the construction process. How to respond effectively has become an important criterion for measuring the professionalism of highway and bridge construction personnel. Professionals with rich knowledge and relevant construction experience have become the key to dealing with emergencies. They can eliminate faults or minimize their losses in a short period of time to ensure the maximum benefit of the project. For example, mechanical equipment failure not only affects normal construction operations, but may also endanger the safety, life and property of construction personnel. Teams with relevant experience should respond promptly in the event of a mechanical failure to prevent secondary injuries and maintain the best interests of the construction party.

Therefore, it is also extremely important to do a good job in the safety management and control of construction machinery. Specific enhancements can be made from several aspects:

(1) Combining engineering features, select corresponding mechanical equipment, and check whether the parameters of the equipment meet the construction requirements before the equipment enters the site.

(2) Do a good job in the daily maintenance of the primary mechanical equipment, and replace the damaged parts in a timely manner to reduce the occurrence of unsafe accidents. In addition, the relevant management departments should also do a good job in filling in the registration manual for the daily use of machinery and equipment, and formulate relevant maintenance plans in accordance with the construction arrangements to ensure the sound operation of machinery and equipment.

(3) Timely replacement of mechanical equipment with a long service life.

(4) Real-time monitoring of mechanical equipment, once any problems are found, stop using it immediately, and the mechanical equipment can be used only after passing the test.

Among the many influencing factors of highway and bridge construction safety, the impact of construction environment on construction safety is also very large. Weather such as strong wind and rainfall has increased the risk of construction safety hazards. Therefore, it is very important to do a good job in safety management and control of the construction process, and relevant measures can be taken to control:

(1) Reasonable control of the daylighting and lighting system. During construction, daylighting should 
be good, so that it is convenient for construction personnel to work, especially at night or when construction is in dimly lit areas, and sufficient light sources should be ensured. This way, on the one hand, it can provide construction personnel with a bright working environment, and on the other hand, It can also reduce the occurrence of unsafe accidents.

(2) Scientific arrangement of construction time. If the construction environment temperature is too high, it will make the construction personnel in a high temperature environment, which will easily cause dizziness for a long time. If the construction environment is too low, it will also make the construction personnel feel uncomfortable and affect the construction progress. Therefore, scientific arrangements should be made in accordance with the environmental temperature characteristics. The construction time creates a suitable construction environment for the construction personnel and improves the effectiveness of the construction.

(3) Do a good job in construction site management. The site must be thoroughly cleaned before construction, and the selected machinery should be noise reduction equipment to create a comfortable working environment for the construction personnel.

(4) Different from other parts of the construction, the high-altitude operation has a complicated geographical location. As a construction worker, it is necessary to raise awareness and strictly follow the corresponding process during the construction. Before construction, safety clarification work should be carried out step by step, and the required equipment should be prepared in place. Construction personnel should wear safety helmets and safety belts. It is strictly forbidden to implement continuous availability payment on an annual basis with hidden safety hazards, but pay for operating services .

To sum up, in the safety risk assessment of highway bridges, it is still necessary to consider actual factors and adjust the countermeasures to control risks in combination with different actual characteristics.

\section{Conclusion}

According to the design principles of the safety risk evaluation index for urban highway and bridge construction, the evaluation index system is determined, and the subtle indexes of environmental factors, equipment factors and management factors are classified, and the functions of all levels of the evaluation index system are analyzed in detail. It also analyzed the management and control measures after the risk assessment, determined reasonable management and control measures, and clarified the focus on management content of the road bridge construction safety risk in the later period.

\section{References}

1. Wei Wei, Igarashi Akira,Zhu Hongping,Tan Ping. Experimental investigation and seismic fragility analysis of isolated highway bridges considering the coupled effects elastomeric bearings[J]. Structures, 2021,233.

2. Heng Kai,Li Ruiwen,Li Zhuoran,Wu Hao. Dynamic responses of highway bridge subjected to heavy truck impact[J]. Engineering Structures,2021,232.

3. Nahangi Mohammad,Guven Gursans,Olanrewaju Bolaji,Saxe Shoshanna. Embodied greenhouse gas assessment of a bridge: A comparison of preconstruction Building Information Model and construction records[J]. Journal of Cleaner Production, 2021,295.

4. Weihong Cai, et al.. "A personalized QoS prediction method for web services via blockchain-based matrix factorization." Sensors 19.12 (2019): 2749.

5. Rogulj Katarina,Kilić Pamuković Jelena,Jajac Nikša. Knowledge-Based Fuzzy Expert System to the Condition Assessment of Historic Road Bridges[J]. Applied Sciences,2021,11(3).

6. Tao Weifeng,Lin Peihui,Wang Naiyu. Optimum life-cycle maintenance strategies of deteriorating highway bridges subject to seismic hazard by a hybrid Markov decision process model[J]. Structural Safety,2021,89.

7. Ghasemi Seyed Hooman,Lee Ji Yun. Reliabilitybased indicator for post-earthquake traffic flow capacity of a highway bridge[J]. Structural Safety,2021,89.

8. Deng Yang, et al. "Predicting fatigue damage of highway suspension bridge hangers using weigh-inmotion data and machine learning." Structure and Infrastructure Engineering 17.2 (2021): 233-248..

9. Alogdianakis Filippos,Dimitriou Loukas,Charmpis Dimos C.. Pattern Recognition in Road Bridges' Deterioration Mechanism: An Artificial Approach for Analysing the US National Bridge Inventory[J]. Transportation Research Procedia,2021,52.

10. Xin Du, et al. "A Novel Data Placement Strategy for Data-Sharing Scientific Workflows in Heterogeneous Edge-Cloud Computing Environments." 2020 IEEE International Conference on Web Services (ICWS). IEEE, 2020.

11. Javadinasab Hormozabad Sajad, Gutierrez Soto Mariantonieta. Load balancing and neural dynamic model to optimize replicator dynamics controllers for vibration reduction of highway bridge structures[J]. Engineering Artificial Intelligence, 2021,99.

12. Wang Xiaowei,Pang Yutao,Ye Aijun. Probabilistic seismic response analysis of coastal highway bridges under scour and liquefaction conditions: does the hydrodynamic effect matter[J]. Advances in Bridge Engineering,2020,1(1). 